\title{
Book review: Learning to Think: Disciplinary Perspectives
}

Donald, J. (2002). Learning to think: disciplinary perspectives. San Francisco, CA, Jossey-Bass.

\section{Jerry Spring}

Zayed University, UAE

In this fascinating book, Janet Donald reviews and synthesizes over two decades of research, to which she has made a central contribution, about developing student thinking in higher education. Her book has two main focuses: first, the ways that students' knowledge and thinking are structured in different academic disciplines; second, the ways that instructors can best help students develop those knowledge structures and thinking processes.

Because of critical role that higher education in the Gulf can play in improving student thinking, his book is likely to be of great interest to higher educationalists in the Gulf region - both researchers and instructors. If you are a researcher, then Donald's comprehensive summary of the research literature will suggest a multitude of research projects into the development of student thinking that have yet to be done in this region. If you are an instructor, the book will surely encourage you to look afresh at the conceptual structure of your courses and the precise ways of thinking that your courses inspire in students (particularly when it contrasts strongly with the modes of thinking they have developed through their previous educational experiences). A great strength of the book is that Donald draws on data from a wide range of disciplines (primarily physics, engineering, chemistry, biological sciences, psychology, law, education and English literature). Consequently, whatever your discipline, there are likely to be enough applicable findings and suggestions to make this book a worthwhile read.

Another strength of the book is the range of data that Donald draws on to develop her model of student thinking, and to support her general conclusions and suggestions. This includes both qualitative and quantitative approaches; data from both students and instructors; subjective reports about views on teaching and learning versus objective documentary and observational data about course design, materials, classroom activities and assessment practices; samples from the USA, Canada, the UK and Australia; and, as just mentioned, a range of academic disciplines. In passing, it's worth bearing in mind that, whilst Donald primarily draws her evidence from particular instructional courses, she wishes these examples to stand for the respective disciplines they belong to. I am not sure whether this is entirely justified, but in this review I generally refer to 'disciplines' rather than 'courses'.

In the opening chapter, Donald clearly sets out and justifies an organizing framework in relation to previous theorizing about the nature of an academic discipline. On the way, she identifies four components of academic disciplines and higher educational courses: the key concepts, and their nature; the way that these concepts are linked together into a knowledge structure; the way the discipline validates knowledge through specific criteria and processes; the thinking processes the discipline uses to create new disciplinary knowledge.

Donald presents a number of diagrams showing the way key concepts are linked together in specific courses from different disciplines. I found these particularly intriguing for the way they revealed sharp contrasts between, for example, courses with just a few central concepts, from which radiated other concepts like a brainstorming session, and courses where concepts fell into a tidy hierarchy like a

Spring, J. (2008). Book review: Learning to Think: Disciplinary Perspectives. Learning and teaching in higher education: Gulf perspectives, 5(2). http://www.zu.ac.ae/Ithe/lthe05_02_06_spring.htm 
family tree. It made me wonder if we can do more to help students mirror that structure in their own minds - perhaps by presenting similar diagrams regularly in a course. Donald's outlining of the widely divergent ways that different disciplines create and validate knowledge made me think about what happens to students' minds (especially in the first year of many higher education programs) as they move, within the same day, between thinking, for example, as literary critics, then as sociologists, then as IT specialists.

The chapter ends with a model showing how different thinking processes (e.g. description, inference) interact with discipline-specific methods of inquiry (e.g. hermeneutics, scientific method). You might ask yourself how many of these thinking processes your students engage in and whether that matches with how you would like them to think, given the discipline they are supposedly engaged in. In short, it can take a long time to get through this chapter because it so strongly invites us wander off on paths of speculation about our students' thinking, the design of our courses, and the nature of our discipline.

In the next seven chapters, Donald employs her theoretical framework to organize her review of the data on student thinking. The chapter headings give a helpful sense of her basic view of the thinking task confronting students in each of the disciplines she considers: 'orderly thinking: learning in a structured discipline' (physics); 'hard thinking: applying structured knowledge to unstructured problems' (engineering); 'inductive thinking: knowledge-intensive learning' (chemistry, biology); 'multifaceted thinking' (psychology); 'precedent and reason: case versus logic' (law); 'organizing instruction and understanding learners' (education); 'criticism and creativity: thinking in the humanities' (English literature). In each chapter, she presents evidence about the way courses are structured (both in ways that promote and hinder the development of disciplinary thinking), before ending with ideas on how best to meet the challenge of teaching students to learn and think well in that discipline. Donald provides numerous diagrams and tables that show particularly clearly how her overall framework is instantiated in particular courses, and in comparison with other disciplines.

In her final chapter, Donald compares teaching, learning and thinking in the different disciplines in the light of her previous chapters. Her pedagogical aim in this chapter is to summarize the key differences and commonalities in order to suggest how to go about improving teaching and learning across disciplines and particular courses. Her theoretical aim is to integrate two rather different perspectives on thinking: the cognitive perspective that focuses on the learner as an individual problem solving machine, and the social cultural perspective that stresses the importance of social context and community on thinking processes. In this sense she rejects the idea that one fundamental psychological model can describe thinking across disciplines. The evidence she presents in the book clearly shows that this is too simplistic. At the same time, however, she does not wish to accept that there is no commonality between the thinking processes of students across different disciplines; that it is just so much discourse. Instead, she argues from the research evidence that there are six general thinking processes (description, selection, representation, inference, synthesis and verification) that will be employed to a greater or lesser degree in different courses and disciplines.

Some readers may disagree with her theoretical conclusions here. Certainly there is lively debate in both psychology about how to model human thinking and in education about the degree to which there really are transferable thinking skills. However, covering these disagreements is beyond the scope of Donald's book, and, at least for instructors, Donald's framework as it is provides a valuable tool for thinking about teaching and learning. Since this book appeared, a number of researchers have been developing the notion of 'threshold concepts' (e.g. Meyer and Land, 2003; 2005; Shanahan et al., 2006). These are conceptual doorways that lead students into transformed and sometimes troubling ways of

Spring, J. (2008). Book review: Learning to Think: Disciplinary Perspectives. Learning and teaching in higher education: Gulf perspectives, 5(2). http://www.zu.ac.ae/Ithe/lthe05_02_06_spring.htm 
seeing the world (e.g. precedent in Law, depreciation in Accounting, entropy in Physics). It would be interesting to see this new work married with the approach of researchers such as Donald. In Donald's concept diagrams that I mentioned earlier, which of those concepts, if any, might be a 'threshold' concept? Or, is there a threshold concept that lies hidden as an assumption behind an instructor's teaching that needs to be made explicit to students if they are to really think in the discipline? To give a possible example, in my teaching of essay writing, I believe that there is a particularly troublesome threshold concept: the idea of an essay prompt as a problem to solve (rather than a clue to a formula). Perhaps my teaching should be more clearly organized around this concept, if passing through this conceptual doorway is a necessary (and troubling) step for students to take in order to think about essay writing in the way I think they need to.

If there is one take-home message from this book, it is that the task of improving student thinking cannot be reduced to a few teaching techniques that can be universally applied across courses. If, as higher educationalists, we are committed, not simply to filling students' heads with information to regurgitate in exams (and then forget), but rather to encouraging them to become apprentice thinkers within our disciplines (and then hopefully lifelong thinkers), then Janet Donald's book will assist us in finding a way through the complexities that she reveals.

\section{References}

Meyer, J. and Land, R. (2003). Threshold concepts and troublesome knowledge: linkages to ways of thinking and practising within the disciplines. In Rust, C. (ed.) Improving student learning: improving student learning theory and practice - ten years on. Oxford: Oxford Centre for Staff and Learning Development, 431-443.

Meyer, J. and Land, R. (2005). Threshold concepts and troublesome knowledge (2): epistemological considerations and a conceptual framework for teaching and learning. Higher Education, 49, 373-388.

Shanahan, M., Foster, G. and Meyer, J. (2006). Operationalising a threshold concept in economics: a pilot study using multiple choice questions on opportunity cost. International Review of Economics Education, 5(2), 29-57. 